\title{
Corrigendum to "Detection of Gastrointestinal Pathogens from Stool Samples on Hemoccult Cards by Multiplex PCR"
}

\author{
Martin Alberer, Nicklas Schlenker, Malkin Bauer, Kerstin Helfrich, Carolin Mengele, \\ Thomas Löscher, Hans Dieter Nothdurft, Gisela Bretzel, and Marcus Beissner
}

Department of Infectious Diseases and Tropical Medicine, Medical Centre, Ludwig-Maximilians-University (LMU), Munich, Germany

Correspondence should be addressed to Martin Alberer; martin.alberer@lrz.uni-muenchen.de

Received 10 April 2017; Accepted 23 April 2017; Published 30 May 2017

Copyright (c) 2017 Martin Alberer et al. This is an open access article distributed under the Creative Commons Attribution License, which permits unrestricted use, distribution, and reproduction in any medium, provided the original work is properly cited.

In the article titled "Detection of Gastrointestinal Pathogens from Stool Samples on Hemoccult Cards by Multiplex PCR" [1], there was an error in Acknowledgments, which should be corrected as follows.

"The authors thank Dr. Florian Battke, Dr. Battke SCIENTIA Inc., for his scientific support. This paper is the result of the doctoral thesis of Nicklas Schlenker. The project was supported by research grants from the Friedrich Baur Foundation, Takeda Inc., and Luminex Inc."

\section{References}

[1] M. Alberer, N. Schlenker, M. Bauer et al., "Detection of gastrointestinal pathogens from stool samples on hemoccult cards by multiplex PCR," Canadian Journal of Infectious Diseases and Medical Microbiology, vol. 2017, Article ID 3472537, 6 pages, 2017. 


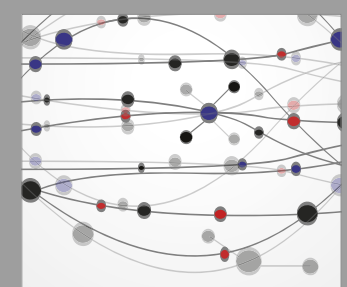

The Scientific World Journal
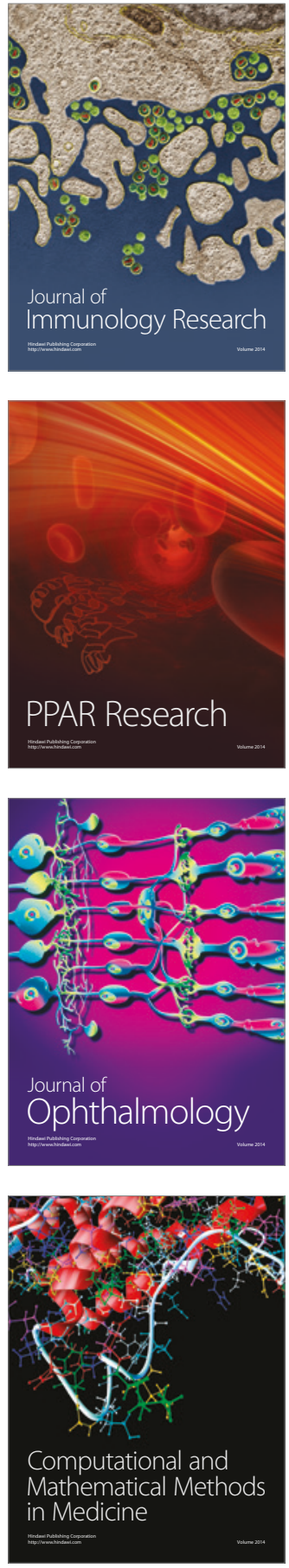

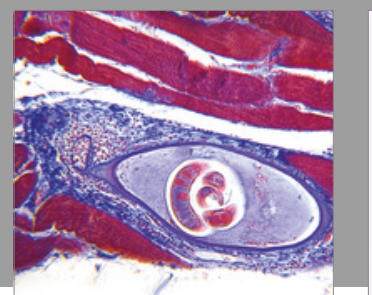

Gastroenterology Research and Practice
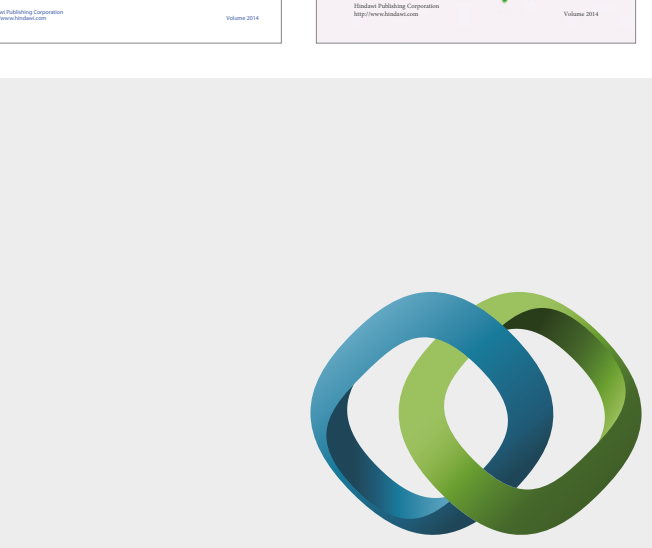

\section{Hindawi}

Submit your manuscripts at

https://www.hindawi.com
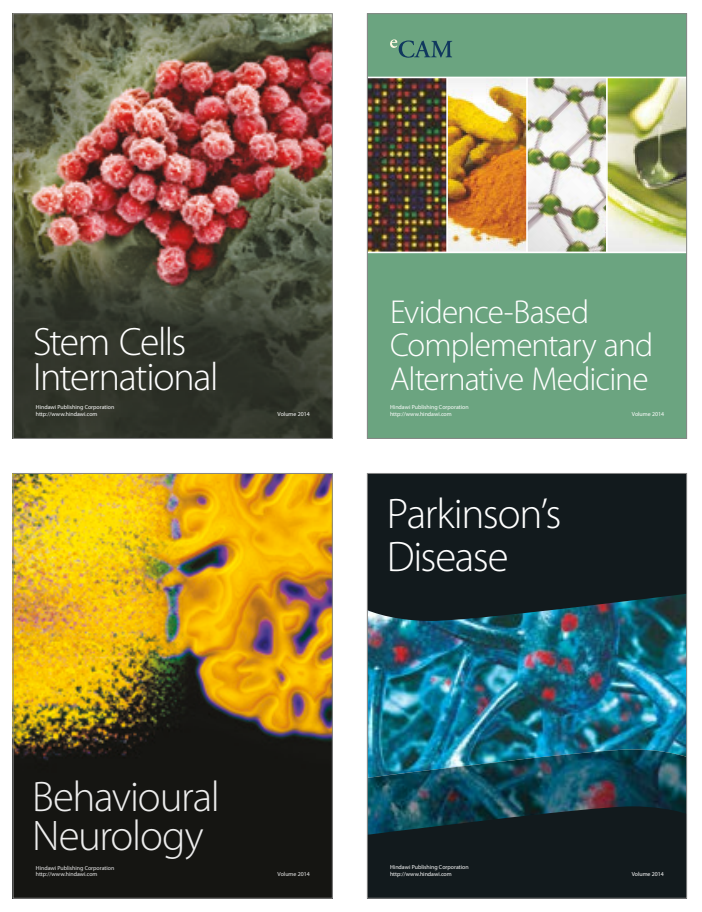
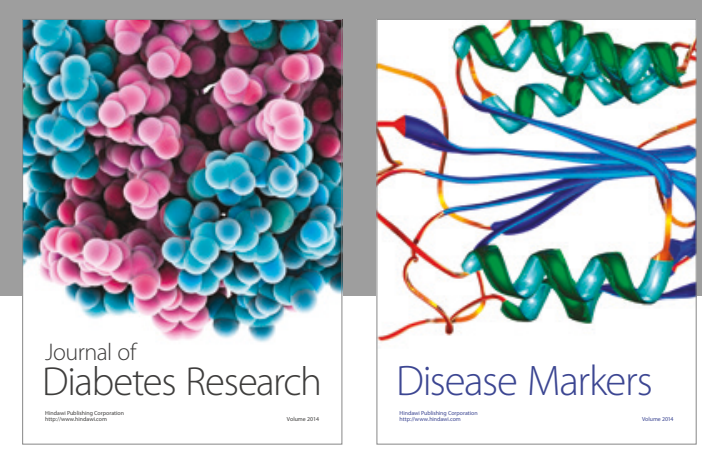

Disease Markers
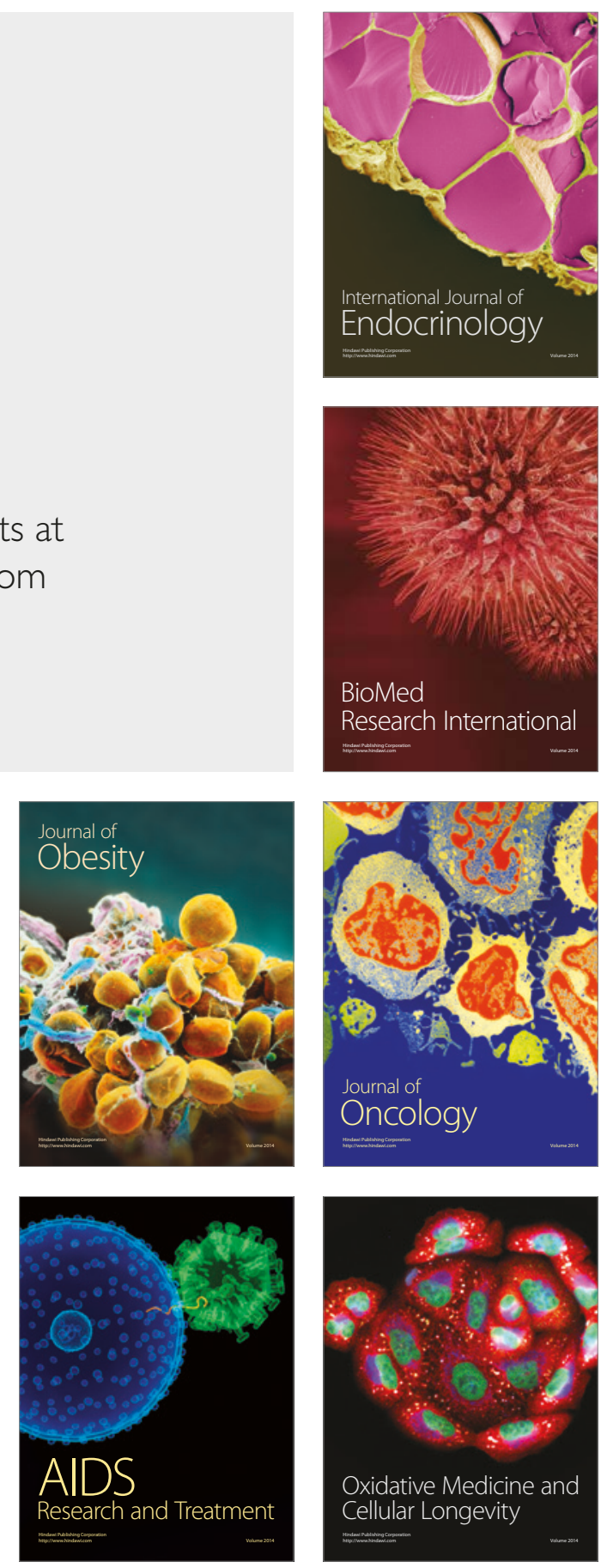